\title{
Mediating and catalysing innovation: A framework for anticipating the standardisation needs of emerging technologies
}

\author{
Charles R. Featherston*, Jae-Yun Ho, Laure Brévignon-Dodin, Eoin O’Sullivan \\ Centre for Science, Technology and Innovation Policy, Institute for Manufacturing, University of Cambridge \\ 17 Charles Babbage Road, Cambridge CB3 OFS, United Kingdom
}

\begin{abstract}
The development of technology strategies are often supported by strategic frameworks. Although standards can be critical in fostering technological innovation, particularly by supporting knowledge diffusion, their importance is often neglected by commonly used strategic frameworks. This paper presents a framework which uses a characterisation of transition needs between key anticipated innovation activities to anticipate standards needs for emerging technologies. The framework draws attention to strategic considerations and dimensions that might otherwise be overlooked, including different types of standards; standardisation stakeholders; the alignment, coordination, and sequencing of standards; and how these all change over time. Technology roadmapping based framework was used to explore standardisation needs because it explicitly characterises the last two of these and provides a framework for exploring the remainder. The principles and utility of the framework are demonstrated in three contrasting case studies: synthetic biology, additive manufacturing, and smart grid. These show how standards mediate between innovation actors by codifying and diffusing knowledge and can enhance and catalyse innovation. The proposed framework can be used to reveal where standards might be used to support innovation, better characterise the types of standards needed, identify the stakeholders needed to develop them, and highlight any potential alignment, coordination, and sequencing issues related to standardisation activities.
\end{abstract}

\section{Introduction}

Many national governments and executive agencies are taking strategic approaches to supporting key emerging technologies in order to accelerate economic growth and overcome social and environmental challenges (HLG KET 2011; NSTC 2011a; NSTC 2014; Willetts 2013). At the same time, there is growing understanding of the role and importance of standardisation in technological innovation, and the potential for technical standards to offer a source of competitive advantage in new industries (Lundvall 1992; Van de Ven 1993a; Metcalfe and Miles 1994; Ehrnberg and Jacobsson 1997; Smith 1997; Tassey 2000; Bergek et al. 2008; Swann 2010). Of particular interest to national governments and supranational bodies (c.f. European Commission 2011; CEN and CENELEC 2012; 2014; Lord Heseltine 2012) are the opportunities standards offer to help codify diverse types of technical knowledge, which can be important from the very earliest stages of emerging technology innovation and relevant to a range of different innovation activities and actors (Sherif 2001; Tassey 2000; Blind and Gauch 2009; Swann 2010).

Although standardisation is increasingly highlighted in governmental policies for emerging technologies and associated foresight analyses (Bourell et al. 2009; TSB 2012; NSTC 2014), only recently have attempts been made to identify standardisation needs and challenges in a systematic and comprehensive 
way (e.g. TESSY 2008; NIST 2010; 2012; 2014; European Commission 2013; SASAM 2014; Scapolo et al. 2014).

It is accepted that not all standards are developed through formal standardisation processes (US International Trade Commission, 1990; Metcalfe \& Miles, 1994; Allen \& Sriram, 2000; Tassey, 2000; Wang \& Kim, 2007). However, attempts to anticipate the standardisation needs of emerging technologies is, of course, challenging. This is partly because of the non-linear, highly complex, and highly uncertain nature of innovation. It is also because standardisation processes are complex and dynamic, involving: high levels of technical detail and consensus; various types of standards in terms of both roles and developing organisations; different motivations and requirements from stakeholders; and the integration of information relevant for standards development which is distributed among a variety of innovation system actors (Allen and Sriram 2000; Tassey 2000; Sherif 2001; Wang and Kim 2007; Swann 2010; Blind et al. 2010). Furthermore, given this complexity, there is significant potential for competing standards visions or premature consensus to emerge, leading to ineffective or even counterproductive standards (Foray 1998; Tassey 2000; Swann 2010).

Given these opportunities to support innovation and enhance technology strategies, and the related difficulties, there is an increasing awareness of the importance of developing robust frameworks and processes for anticipating standards more effectively (NSTC 2011b; European Commission 2011; Lord Heseltine 2012). In particular, there is recognition of the potential value of new foresight approaches which could more clearly link opportunities for standardisation to specific innovation activities and the R\&D needs of emerging technologies (European Commission 2011, Scapolo et al. 2014).

This paper proposes a structured approach, grounded in technology roadmapping, for exploring the potential standardisation needs of emerging technologies. The proposed framework for the approach, which emerged from a series of systematic studies conducted for the British Standards Institute and the UK Department of Business, Innovation and Skills (Featherston et al. 2014; Ho and O'Sullivan 2013; Brévignon-Dodin and O’Sullivan 2013; O’Sullivan and Brévignon-Dodin 2012), highlights important factors that need to be accounted for when developing standardisation strategies. These include: (a) important categories of innovation activities which may require supporting standardisation; (b) different categories or types of standards (i.e. codifying different types of technical knowledge); (c) the diverse and evolving sets of stakeholders involved in standards development processes; and (d) the timing and sequencing of standards development (and revisions).

The principles of the framework are demonstrated using recent 'historical examples' of standards development for three important but contrasting emerging technologies: synthetic biology, additive manufacturing, and smart grid. The case studies suggest that the structured and time-orientated view of technology development provided by the established technology roadmapping framework can be leveraged to support the anticipation of standardisation needs and opportunities.

\section{Conceptual foundations}

\subsection{Standards and their contribution to innovation}


Although there are variations in how the term 'standard' is defined, the following key common elements are included in multiple definitions by scholars and practitioners: established by consensus; approved by a recognised body; provide 'rules, guidelines or characteristics for activities or their results'; 'aimed at the achievement of order' and coherence in technical or commercial activities, particularly to ensure that users have confidence that codified knowledge, materials, products, processes, and services, among others, are 'fit for purpose' (Allen and Sriram 2000; ISO 2004; BSI 2006; Blind and Gauch 2009; Hatto 2010, p.5; Ho \& O’Sullivan, 2014). Standardisation is the pursuit of these through conformity, has a number of motivations, and is driven by a variety of innovation actors (Metcalfe \& Miles, 1994; Tassey, 2000, p.588). However, the key difference is that standardisation often occurs, at least to a certain extent, and is sometimes inevitable, whether a standard is acknowledged or formally established or not.

Standards (and standardisation) may have both positive and negative impacts on innovation (Swann 2000; Tassey 2000). Despite their potential to constrain certain innovation activities, carefully constructed and implemented standards can create an infrastructure that supports transferring innovative ideas, hence facilitating innovation.

There is a long tradition of academic work (for example, Brady 1933) exploring the potential for standards to obstruct innovation by limiting technological variety. Hanseth et al. (1996, p.408), for example, argue that standards 'increase irreversibility and decreases interpretative flexibility of the technologies.' Standards may result in problems of lock-in to inferior standards or the risks of monopoly, which are potentially detrimental to innovation (Swann 2000). For example, health and safety standards for consumer protection may lead to firms focusing on fewer innovative technologies, which, in turn, results in reduced consumer choice (BERR 2008). As Foray (1998, p.81) puts it, there are two apparently contradictory logics 'that of freedom, creativity and dynamics related to innovation and that of stability, order and routine associated with standards.'

Recently, there is a growing understanding that standards, more generally, play critical roles in supporting various activities of innovation. For example, in a bibliometric analysis, Choi et al. (2011) demonstrate that well-designed standards support various innovation activities. A number of recent studies support these findings and suggest standardisation performs important functions in support of innovation. They include: defining and establishing common foundations upon which innovative technology may be developed (NSTC 2011a); codifying and diffusing state of the art technology and best practice (Tassey 2000), making them available as a basis for further innovation (Allen and Sriram 2000; Swann 2010; Hatto 2010); and allowing interoperability between and across products and systems, stimulating both innovation and diffusion of new technologies integrated into a system (Tassey 2000; Blind and Gauch 2009).

Of particular interest in the context of this paper is the 'mediating' function of standards - diffusing new knowledge between innovation actors. This function has been highlighted in a number of academic and practical literatures (Allen and Sriram 2000; Tassey 2000; Blind and Gauch 2009; EXPRESS 2010; European Commission 2011). The European Commission (2011, p.6) identifies standards as highly effective mechanisms for knowledge transfer, helping 'to bridge the gap between research and marketable products or services.' The Expert Panel for the Review of the European Standardisation System (EXPRESS 2010, p.16) also notes that 'standardisation converts new knowledge from scientific research into market' through various types of standards. In addition, Blind and Gauch (2009) identify a variety of standards with different roles and how they support knowledge diffusion between and across various 
stages of innovation, including: terminology standards and measurement standards helping transfer knowledge from basic to applied research; interface standards facilitating the gap between applied research and experimental development of new products and processes; and variety reduction standards fostering diffusion of knowledge in new products. Frameworks are needed to help better reveal standardisation needs and where standards might support innovation by matching these needs to particular standards based on the specific roles and functions they perform.

\subsection{Frameworks for understanding technological innovation (and supporting technology strategy development)}

To better reveal standardisation needs, the innovation process itself needs to be characterised in more detail. This section briefly discusses frameworks for understanding technological innovation and structuring technology foresight, and how they have been configured to anticipate standards.

A number of conceptual frameworks have been developed to better understand the systems and processes involved in the innovation and development of emerging technologies (e.g. Tassey 2005; Tassey 2007; Geels 2002; Utterback 1994; Sahal 1985; Dosi 1982; Van de Ven 1993b). Such frameworks pay particular attention to more careful distinctions between different types of technologies, innovation system activities, and the institutions that support innovation. Related innovation systems literature also acknowledges the functions standards can play in innovation, such as legitimising new technologies and diffusing knowledge and know-how that are critical for the innovation process itself (Lundvall 1992; Ehrnberg and Jacobsson 1997; Bergek et al. 2008; Swann 2010).

There is a complementary strand of literature on strategic frameworks designed to support the development of technology foresight or planning (Garcia and Bray 1997; Kostoff and Schaller 2001; Popper 2008; Phaal et al. 2010). Foresight frameworks, like technology roadmapping, are typically quite flexible and scalable; their architectures are readily reconfigurable to include key categories of innovation activities relevant to the foresight topic (Phaal et al. 2004; Lee and Park 2005). Nevertheless, there has been limited exploration of how particular frameworks for such foresight analysis (e.g. technology roadmapping architectures) might be used to facilitate more effective identification and timely anticipation of important opportunities for standardisation. Although there have been a few scholarly attempts to establish frameworks that explore the evolving and varied roles of standards in the technological innovation and development (e.g. Tassey 2000; Sherif 2001; Blind and Gauch 2009), none of these frameworks effectively capture all factors that are essential in identifying standardisation needs.

Due to this gap in foresight research and practices, standards are typically not addressed in significant detail in recent governmental technology strategies and roadmaps (e.g. TSB 2012; HLG KET 2011; BMBF 2010). There is especially limited exploration of standardisation needs at the earlier stages of precompetitive development as technologies emerge from the research base. This is despite calls by the European Commission and other national governments for facilitating researchers to engage more actively in standards development earlier in the innovation process (European Commission 2011; Lord Heseltine 2012).

To inform the design of a framework for anticipating standards needs for emerging technologies, the key characteristics of standards and their development challenges need to be understood. The remainder of section 2 is dedicated to drawing out these characteristics and challenges. 


\subsection{Characterising standards and standardisation}

Standards can be classified or categorised in a number of different ways. A common way of distinguishing between standards is their de facto or de jure status (cf. Allen and Sriram 2000; Wang and Kim 2007; Hatto 2010; ANSI 2014). Other means of classifying standards are by the expertise and focus of the standards development organisation (SDO) leading the standards development process and the types of technical knowledge and information the standards are designed to codify and disseminate. These last two are discussed in more detail in the following sections.

\subsubsection{Different standards development organisations, with different expertise and focus}

Standards are sometimes differentiated by the different expertise and focus of SDOs leading the standards development process. Formal consensus standards are published by technical committees of national standards bodies (e.g. BSI, DIN and AFNOR), multinational standards bodies (e.g. CEN, CENELEC and ETSI), or international standards bodies (e.g. ISO, IEC and ITU), whereas informal standards are generally published by private non-profit (industry-driven) SDOs (e.g. ASTM) (Hatto 2010). Private standards are also developed by companies or trade associations. In addition, there are other important organisations involved in standards development, especially in the context of this paper's exploration of emerging technologies, including: professional engineering or scientific associations (e.g. IEEE, VDI and IET), working groups of international consortia (e.g. W3C, OMG and IETF) and research consortiums / research initiatives (e.g. BioBricks) (O’Sullivan and Brévignon-Dodin 2012). Different organisations leading standards development often have different standardisation missions, contributions and participation. Variations in the stakeholders involved in the standardisation process, and how these vary over time, are discussed further in section 2.4.2 below.

\subsubsection{Different categories of standard: Characterised by type of technical knowledge codified}

Of particular importance in the context of this paper - given its focus on strategy development for emerging technologies - are the categories of standards distinguished by the different types of technical knowledge they codify. These include:

- Terminology and semantic reference standards define common language and definitions to facilitate efficient communication among various stakeholders (Blind and Gauch 2009; BERR 2008).

- Measurement and characterisation standards specify methods for describing, quantifying, and evaluating product attributes for efficient R\&D (Blind and Gauch 2009; Hatto 2010).

- Quality and reliability standards specify acceptable performance criteria along dimensions such as functional levels, efficiency, and health and safety (BERR 2008; Tassey 2000).

- Compatibility and interface (interoperability) standards specify properties that a technology must have in order to be compatible (physically or functionally) with other products, processes, or systems (Blind and Gauch 2009; BERR 2008).

- Configuration standards (which can result in variety reduction) specify ranges, numbers, formats, architectures, or characteristics such as size or quality levels, to promote economies of scale and bolster users confidence (Swann 2010; Hatto 2010; Tassey 2000).

This variety of standards, the variety of complex technical activities with potential for standardisation, and the large number of stakeholders involved in standards development, makes the comprehensive and systematic analysis of future standardisation needs of emerging technologies challenging. A framework 
that attempts to systematically analyse future standardisation needs should also consider the evolving contribution of standardisation to emerging technologies and their implications for technology foresight.

\subsection{Standards and emerging technologies: The challenges for technology foresight}

Critical to any technology foresight analysis is its ability to explore, in sufficient technical detail, how different innovation activities, challenges, and opportunities may evolve over time. In the case of foresight efforts to anticipate the standardisation needs of emerging technologies, careful and systematic attention needs to be paid to: different standardisation requirements at different stages of emerging technology development (including standards for generic technologies and infrastructure); the evolving composition and motivations of stakeholders over time; and the implications of timing (i.e. sequencing) of different standards for other standardisation efforts and innovation activities.

There have been some efforts to carry out such analyses in practice, with varying emphases and approaches. For instance, an initiative launched in 2010 by the National Institute of Standards and Technology (NIST) in the US aimed to coordinate the development of standards for smart grid, acknowledging standards-related opportunities and challenges within a broad technology roadmap (NIST 2010; 2012; 2014). The NIST initiative allowed the identification of relevant standards in the technological domain while pointing at priority gaps and harmonisation issues (NIST 2010). It also provided a conceptual framework to depict different stakeholders involved in smart grid and how they interact with each other. In addition, it paid special attention to the actors involved in standards development, highlighting instances where coordination between Federal agencies and industry groups is required.

The EU 'Towards a European Strategy in Synthetic Biology' (TESSY) project offers another example of an attempt to consider standards development in a strategic way (TESSY 2008). Concerned with developing a vision for synthetic biology and assisting in shaping innovation policy, the TESSY roadmap pays special attention to timing- and sequencing-related issues and identifies four consecutive standardisation phases as part of a broader regulation dimension.

SASAM's (2014) additive manufacturing standardisation roadmap focuses on the timing of standards and classifies them with respect to process/ product, materials, and productivity. However, the specific role of the standards and to which innovation activities they relate is not clearly outlined. Additional insights can be provided by the US Roadmap for Additive Manufacturing (RAM) which was published in 2009 (Bourell et al. 2009). Its overarching objective was to articulate a vision for research in the domain of additive manufacturing and identify priority R\&D areas with high potential. Although it did not solely focus on standards, its systematic approach brought clarity on identifying standards-related needs and on the involvement of the additive manufacturing community in standards development (Bourell et al. 2014).

The above exercises demonstrate the value of a number of different considerations when anticipating standardisation needs, including: evolving standardisation requirements, the evolving composition and motivations of stakeholders, and the timing and sequencing of standards. However, none of the studies fully address all these considerations. The following sections discuss these considerations and dimensions in more detail and why they should be accounted for in foresight exercises that aim to anticipate the standardisation needs of emerging technologies. 


\subsubsection{Evolution of standardisation requirements at different stages of technology development}

Standards perform various functions at different stages of technology development, and a number of scholars have identified that there are evolving levels of emphases on different types of standards at different phases in the emergence of a new technology. Blind and Gauch (2009) argue that as research and innovation progress, various types of standards are needed, playing different roles at different phases of the innovation journey. Tassey (2000) has also developed a framework representing how various types of standards with different roles are required throughout different stages of industrial activities for efficient development and utilisation of technology. In addition, Sherif (2001) has proposed a framework relating different types of standards with various stages of a technology's lifecycle, from anticipatory standards developed at the introduction of the technology, to participatory standards adopted when the performance improves, followed by responsive standards developed as technology matures. This timing relationship between standards and technology lifecycles is essential, with 'different degrees of standardization... [being] optimal at different points in the technology's... evolution' (Tassey 2000, p.601; Sherif 2001). With such conceptual backgrounds, Ho and O’Sullivan (2013) provide empirical evidence which suggests that different types of standards emerge at different stages of technological innovation and development, using the case of photovoltaic technology. Due to the time-dependent characteristics of standards and their dual nature (limiting and supporting innovation activities), the timely and appropriate development of standards is critical for effective support of innovation.

\subsubsection{Evolving composition of standards development stakeholders}

The academic literature on standards and innovation has also stressed the importance of involving innovation stakeholders in standardisation activities and exploring the ways in which their engagement can affect the standards development. For instance, Yoo et al. (2005) consider successful innovation as a collective achievement made possible only by a network of actors from industry, finance, research, and government whose interests are mediated through standards. Mapping out the standardisation landscape for nanotechnology, Blind and Gauch (2008) highlighted the large number of stakeholders interested in standards development and the importance of their participation at certain stages of the innovation process. These stakeholders include: the German standards development organisation (DIN); the German Commission for electrical, electronic, and information technologies (DKE); companies; and research organisations, including universities and privately and publicly funded research organisations and government laboratories.

Public intervention and the roles of government in standardisation activities have also been reported in various publications, drawing the attention of both academics and practitioners. At a theoretical level, Edquist (1999) viewed technical standards as non-market mechanisms that governments could use to foster innovation in technology specific domains. Based on a case study of information technology standards in South Korea, Wang and Kim (2007) explored the conditions under which the government got involved in standardisation activities. Furthermore, NIST (2011) identifies a number of practical modes through which public actors engage in standards development in the US, including convenor/coordinator, technical leader, participant, facilitator, implementer, funder, technical advisor, and coordinator of Federal Agency needs.

In addition to the variety of stakeholders and their different modes of engagement, stakeholders play different roles at different stages of the innovation process, implying that their involvement in the 
development of standards will also change as a technology develops. Furthermore, this suggests that possible sources of funding for standardisation activities from those, public and private, interested in seeing it occur will similarly change. Therefore, there is considerable value in identifying these sources of funding for more effective and strategic management of standardisation activities. Despite this value, the composition and timing of stakeholder involvement tend to be overlooked in policy initiatives that aim to support innovation through the strategic development of standards.

\subsubsection{Timing and sequencing of different standards}

As well as the coordination of standardisation activities relative to various stages of technological innovation, standards also need to be coordinated relative to other standards, particularly as standardisation strategies often involve the development of more than one standard (e.g. SASAM 2014). Tassey (2000) argues that as standards are a complicated system that influence each other, there is potential for competing standards to emerge, resulting in inefficient or even counterproductive standardisation system. Gandal (1995), through a study of the PC software market, also demonstrates that competing standards can create negative network externalities. The coordination, alignment, and sequencing of standards relative to each other are thus important considerations for a systematic and comprehensive analysis of standards needs for emerging technologies.

In summary, an effective foresight framework for exploring the standardisation requirements of emerging technologies needs to account for the following critical strategic considerations and dimensions in appropriate detail:

- $\quad$ Time - Should be the underpinning principle, enabling the framework to reveal the dynamics of innovation and standardisation activities, including sequencing, interdependence, and the changing composition of stakeholders

- Technological innovation activities - Should be identified in appropriate detail to reveal: opportunities for standardisation, where relevant knowledge needs to be transferred, and where user requirements might be defined

- Standards types - Should be identified in a comprehensive way to ensure that standards are developed in a form that is effective for knowledge transfer and diffusion

- SDOs and participants - Should be identified for strategic coordination among stakeholders involved in standardisation activities

One of the most widely used foresight approaches for developing emerging technology strategies is technology roadmapping (e.g. TSB 2012; NASA 2010; Bourell et al. 2009). The fundamental elements of the technology roadmapping framework incorporates the first two considerations and dimensions listed above, namely a time dimension and a structured, systematic way of characterising innovation activities (Phaal et al. 2004; 2010; Phaal and Muller 2009). Technology roadmapping also lends itself to being adapted to consider the remaining two dimensions and considerations: standards types and SDOs and participants.

The following section contains an introduction to technology roadmapping, followed by a discussion of how it was adapted to become the proposed framework for exploring the standardisation requirements of emerging technologies. 


\subsection{Technology roadmapping}

A technology roadmap provides a coherent and holistic view or vision of future technology landscapes and systems, identifying the critical system requirements, the performance targets, and the technology alternatives and milestones for meeting those targets (Garcia and Bray 1997; Kostoff and Schaller 2001; Phaal and Muller 2009).

The technology roadmapping process brings together a team of experts to not only collect, organise, and present the critical information they anticipate will be needed for technology development, but also identify, select, and develop strategic alternatives for desired objectives (Garcia and Bray 1997; Kostoff and Schaller 2001). It is a process that contributes to the definition of technology strategy by bringing consensus and creating a common vision among various stakeholders (Groenveld, 1997; 2007; Popper 2008; Amer and Daim 2010); this is similar to the process of developing standards, suggesting the potential of roadmapping framework for informing standardisation strategy development.

A technology roadmap can take a variety of forms. The fundamental technology roadmapping framework adopted here is described by Groenveld (1997; 2007), Phaal et al. (2004; 2009; 2010), and Phaal and Muller (2009). This framework has a clear time-based strategic planning format and, typically, a graphical representation of innovation activities which facilitates awareness of interdependencies and sequencing issues (Phaal et al. 2004; 2009; 2010; Blackwell et al. 2008). The framework is time-based (horizontal 'axis') with multiple themes (e.g. functions and disciplines) representing key categories of innovation activities necessary to understand and depict the overall innovation system. Three broad thematic questions relevant to any strategy - how, what, and why - align with Groenveld's (1997; 2007) market, product, and technology-R\&D project categories respectively and have been stacked similarly by Phaal et al. (2004) bottom, middle, and top respectively. The time dimension allows these to be mapped in terms of stakeholders' visions and objectives, and the framework as a whole helps map different stakeholder's perspectives and draws out the relationships between those perspectives (Phaal et al. 2009). Such a generic technology roadmap is able to provide a systematic view of complex, dynamic systems, enabling 'the evolution of a complex system to be explored and mapped, supporting innovation and strategy development' (Phaal et al. 2009, p.287). In particular, the roadmap 'layers' (themes) are configured to correspond to the important categories of technological innovation activity which are used to explore key innovation activities (Phaal et al., 2004), their barriers and enablers (Phaal et al., 2004), as well as technology-push and demand-pull drivers of emerging technology innovation (Phaal and Muller, 2009). Technology roadmapping has been adopted in many private (e.g. IBM 2002; Silverman 2002; Cisco Systems 2003; Jereza et al. 2005) and public (e.g. TSB 2012; NASA 2010; Bourell et al. 2009) technology-planning exercises, at least partly for its ability to help understand the innovation activities and contextual factors involved in innovation. This offers the context to explore where standards could be used to support or mediate between these innovation activities.

\subsection{The standards mapping framework}

Typically, when attention is paid to standardisation in emerging technology roadmaps, standards have been usually incorporated as a single category of innovation 'enabler' (Phaal and Muller 2009; Phaal et al. 2010; Phaal et al. 2011; e.g. TSB 2012). However, as stressed by the literature review in Section 2, different standards interact with different innovation activities and support the diffusion of different 
categories of information and knowledge between these activities. In order to more adequately reflect the detail and diversity of the role of standards in emerging technology development, the framework proposed in this article (depicted in Figure 1) distinguishes different standards types (based on the knowledge they codify) and enables these standards to be linked to the innovation activities affected. Linking lines are often used as a roadmapping convention to indicate interdependent between innovation activities and activity sequences. Where standards help mediate between these activities, a circle with an $\mathrm{S}$ symbol placed on the line. Arrows in two directions indicate the 'mediating' function of standards where they transfer knowledge and information between and across various stages of innovation, as Blind and Gauch (2009) suggest. Potential stakeholders are also identified through the actors directly involved in the linked activities. It also allows us to observe complex dynamics between standardisation and other innovation activities occurring within the various themes of the general roadmapping framework over time.

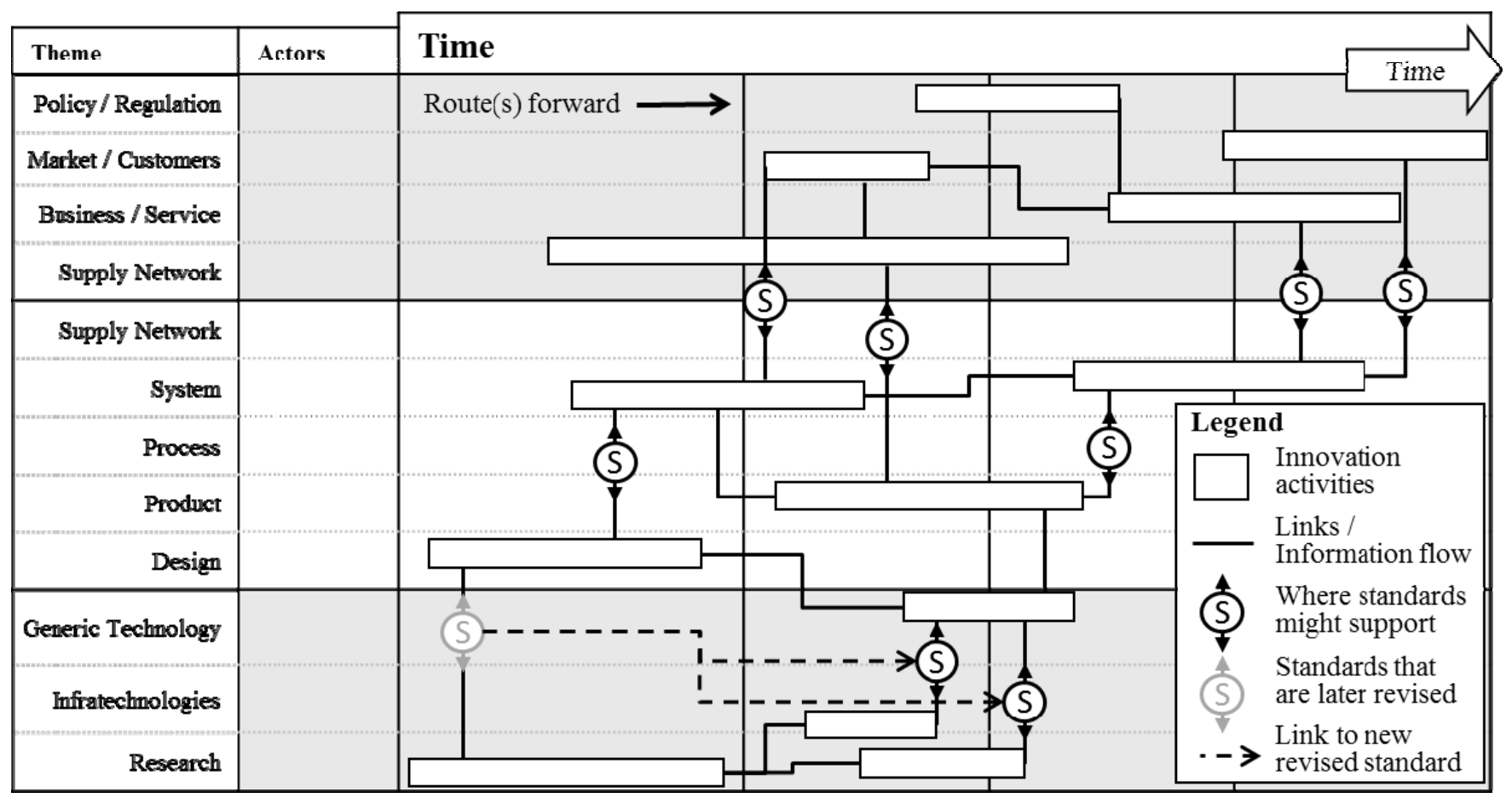

Figure 1: Standards mapping framework, highlighting important categories of innovation activities (based on Phaal and Muller 2009). NB: Supply network is depicted twice because of its dual internal- and external-nature

The vertical axis of the framework (Figure 1) is structured in the same three broad categories as suggested by Groenveld (1997; 2007) and Phaal et al. (2004). The themes are adopted directly from Phaal et al. (2010) and Phaal and Muller (2009), and can be customised to accommodate particular characteristics of technical domains in question. The policy and regulation perspectives have been added because such political and legal aspects play critical roles in standardisation activities and because governments and regulators are key stakeholders in developing standardisation strategies. The bottom section of the framework has been further refined using generic technology - the technological stock that is configured and reconfigured by industry to create proprietary technologies and is replenished from the research base (Tassey, 2005; 2007; Keenan, 2003). Also included are 'infratechnologies' - which support technology development and integration by providing capabilities such as modelling, characterisation, testing, and measurement (Tassey 2005; 2007). Generic technologies and infratechnologies are included not only because they help to characterise innovation more precisely and because they may be an important innovation enabler (Tassey 2005; 2007), but also because they may require standardisation themselves or may be necessary technical bases for standards (Tassey 2000). 
The framework is proposed as a means of capturing the critical considerations and dimensions needed to explore the standardisation needs of emerging technologies drawn out in section 2. It uses the underpinning technology roadmapping framework to elucidate individual innovation activities and, by mapping them over time, their sequences and interdependencies. This provides a canvas for identifying where standards can help diffuse information, informed by the various types of standards that can be employed. The participants involved in the standardisation activities can then be identified based on those involved in the relevant innovation activities and the information being diffused.

Similarly to the technology roadmapping framework, the proposed framework can be adapted to suit a range of situations. For example, grey standards have been added to the depiction of the framework in Figure 1 to indicate standards that have been or will be withdrawn or revised and have been linked to their revised versions by a dotted line with an arrow. This helps to depict the 'system' of standards for an emerging technology.

Essentially, the framework is designed to map various types of standards with different roles and functions, according to relevant dimensions of emerging technology innovation activities and across the stages of the innovation journey. Further, it supports the better articulation and visualisation of how standards-related activities can support the overall innovation system by helping to identify future standards needs to facilitate knowledge diffusion and highlighting any potential coordination, alignment and sequencing issues related to standardisation activities.

\section{$4 \quad$ Case studies}

The framework is applied in three case studies in three different technology domains - synthetic biology (SB), additive manufacturing (AM), and smart grid (SG) - to demonstrate its underlying principles. These domains have been selected because of their contrasting characteristics: they are technologies that are fundamentally different in nature (i.e. a platform technology, a production technology, and a system of technologies), at different stages of maturity, with different actors involved in their development, and with different knowledge structures, Furthermore, standards in the three fields have been developed by different sources and are often developed differently. These case studies build on a series of systematic reviews of emerging technology strategies, standardisation efforts in relation to these strategies, and how standardisation has occurred during their development (Featherston et al. 2014; Ho and O’Sullivan 2013; Brévignon-Dodin and O’Sullivan 2013; O’Sullivan and Brévignon-Dodin 2012).

The case studies use historical examples to demonstrate the principles, and provide representative illustrative examples, of the framework. They depict how potential standardisation needs might be identified based on the knowledge diffusion needs of innovation activities. The case studies use the development and adoption of standards as a proxy for standardisation needs. It was found in the case studies that standards diffuse information between a number of similar activities and as a result these activities have been clustered into broader aggregate activities. The consequence for the case studies (and the implications for the framework) is that they depict standardisation opportunities based on the diffusion needs between clusters of innovation activities.

In each case study a small selection of standards are explained in detail to illustrate the information they codify and the functions they perform. Demonstrating the framework in these three domains provides 
examples of the framework's ability to capture the aforementioned considerations and dimensions that are relevant for understanding the standardisation needs in emerging technologies (see section 2.4) and demonstrates the framework's diversity.

While the additive manufacturing case study includes all formal standards developed specifically for additive manufacturing, too many standards have been developed for synthetic biology and smart grid to depict them all. Instead, a selection of standards was made in these domains to demonstrate the framework's ability to identify standardisation needs that require various types of standards to be developed by a variety of sources.

It should be noted that the representative illustrative examples shown in the case studies depict only the activities and links related to the selected standards to make the mapping manageable. While this neglected several innovation activities and links, it should be remembered that these case studies are a demonstration of the concepts reflected in the framework. The arrows on the links, which are often used to indicate information flow, are also reflected only in the standards symbol itself for visual simplification.

\subsection{Synthetic biology}

Synthetic biology is a rapidly emerging area of biological research. It is concerned with 'the redesign and engineering of biological systems and processes for new uses' by taking 'naturally occurring genes and engineer[ing] new genes and hence [new] organisms' (Willetts, 2013, p.32). The technology is at an early but rapidly developing stage, with potential applications in a vast number of sectors, such as healthcare, energy, environment, chemicals, and materials.

Going from traditional microbiology to some more engineered dimensions biology intrinsically requires standardisation (Endy 2005; Torrance \& Kahl 2012). Decoupling biological design from fabrication, in particular, has led to abstraction- and standardisation- related needs to manage biological complexity (NAKFI 2010). Interest in standardisation activities has therefore been a permanent feature of the synthetic biology community, with researchers getting proactively engaged in standardisation activities (Keasling 2005; Torrance \& Kahl 2012).

Special attention is being paid to standards related to definition and characterisation of parts, data sharing, and measurement because synthetic biology is still at an early stage of development. The relative immaturity of the field is reflected in the technical standards framework launched by the BioBricks Foundation (BBF). Proposing a catalogue of 104 standards, the BBF focuses on those standards associated with early stage research activities like the description of parts, devices and systems; data capture and exchange; and assembly and measurement tools. This catalogue has been used as the reference database to conduct this case study as it is well established and used by synthetic biology researchers. These standards can be considered as 'community-building standards' because they aim to bring cohesion to the variety of stakeholders conducting different research and contributing to the field in a variety of ways.

The BBF standards in Table 1 were selected from the catalogue to represent four roles performed by the standards developed by the BBF community in support of synthetic biology. The roles, and associated types, include physical configuration standards for the physical assembly of individual biological components into larger and multi-component systems; functional configuration standards to inform biological part assembly so they function in a predictable manner; and reference standards in support of measurements and data exchange for the electronic exchange of information on genetic parts and systems (Torrance \& Kahl 2012). A test for the framework was to capture and reflect the roles of these standards with respect to relevant innovation 
activities. Unfortunately the BBF catalogue only provides some dates for the standards, some relating to submission dates and some to the date they were accepted. As a consequence Table 1 shows only the relative chronology of the standards.

\begin{tabular}{|l|l|l|l|}
\hline $\begin{array}{l}\text { Standard } \\
\text { (chronological order) }\end{array}$ & Simplified title & Role & Developer \\
\hline BBF RFC 8 & Early standard design for biological parts & Physical configuration & BBF \\
\hline BBF RFC 11 & Assembly methods & Physical configuration & BBF \\
\hline BBF RFC 18 & $\begin{array}{l}\text { Conceptual guidelines in support of graphical } \\
\text { language }\end{array}$ & Data exchange & BBF \\
\hline BBF RFC 19 & Measurement of activity of promoters & Measurement & BBF \\
\hline BBF RFC 23 & Assembly methods for protein engineering & Physical configuration & BBF \\
\hline BBF RFC 30 & $\begin{array}{l}\text { Framework for the exchange and integration of } \\
\text { data v.1 }\end{array}$ & Data exchange & BBF \\
\hline BBF RFC 32 & $\begin{array}{l}\text { Framework for the exchange and integration of } \\
\text { data v.2 }\end{array}$ & Data exchange & BBF \\
\hline BBF RFC 37 & Assembly methods in support of protein fusion & Physical configuration & BBF \\
\hline BBF RFC 41 & Promoter measurement units & Measurement & BBF \\
\hline BBF RFC 48 & Automated design of biological circuits & Functional composition & BBF \\
\hline BBF RFC 57 & New assembly method & Physical configuration & BBF \\
\hline BBF RFC 59 & $\begin{array}{l}\text { Quantitative measurement method using flow } \\
\text { cytometry }\end{array}$ & Measurement & BBF \\
\hline BBF RFC 69 & Interconnection of parts & Physical configuration & BBF \\
\hline BBF RFC 84 & Synthetic Biology Open Language (SBOL) v.1 & Data exchange & BBF \\
\hline BBF RFC 87 & Synthetic Biology Open Language (SBOL) v.2 & Data exchange & BBF \\
\hline BBF RFC 93 & $\begin{array}{l}\text { Synthetic Biology Open Language Visual } \\
\text { (SBOL Visual) }\end{array}$ & Data exchange & BBF \\
\hline Table 1: Stang & Bargety and varying \\
\hline
\end{tabular}

Table 1: Standards observed in the synthetic biology case study, selected for their variety and varying levels of interdependence

Figure 2 is a representative illustrative example of the standards shown in Table 1 mapped using the principles of the proposed framework. As can be seen, the innovation activities focus predominantly on research, reflecting synthetic biology's early stage of development. The links in Figure 2 indicate where standards have been developed to support the codification and transmission of knowledge between particular (aggregated) innovation activities. 


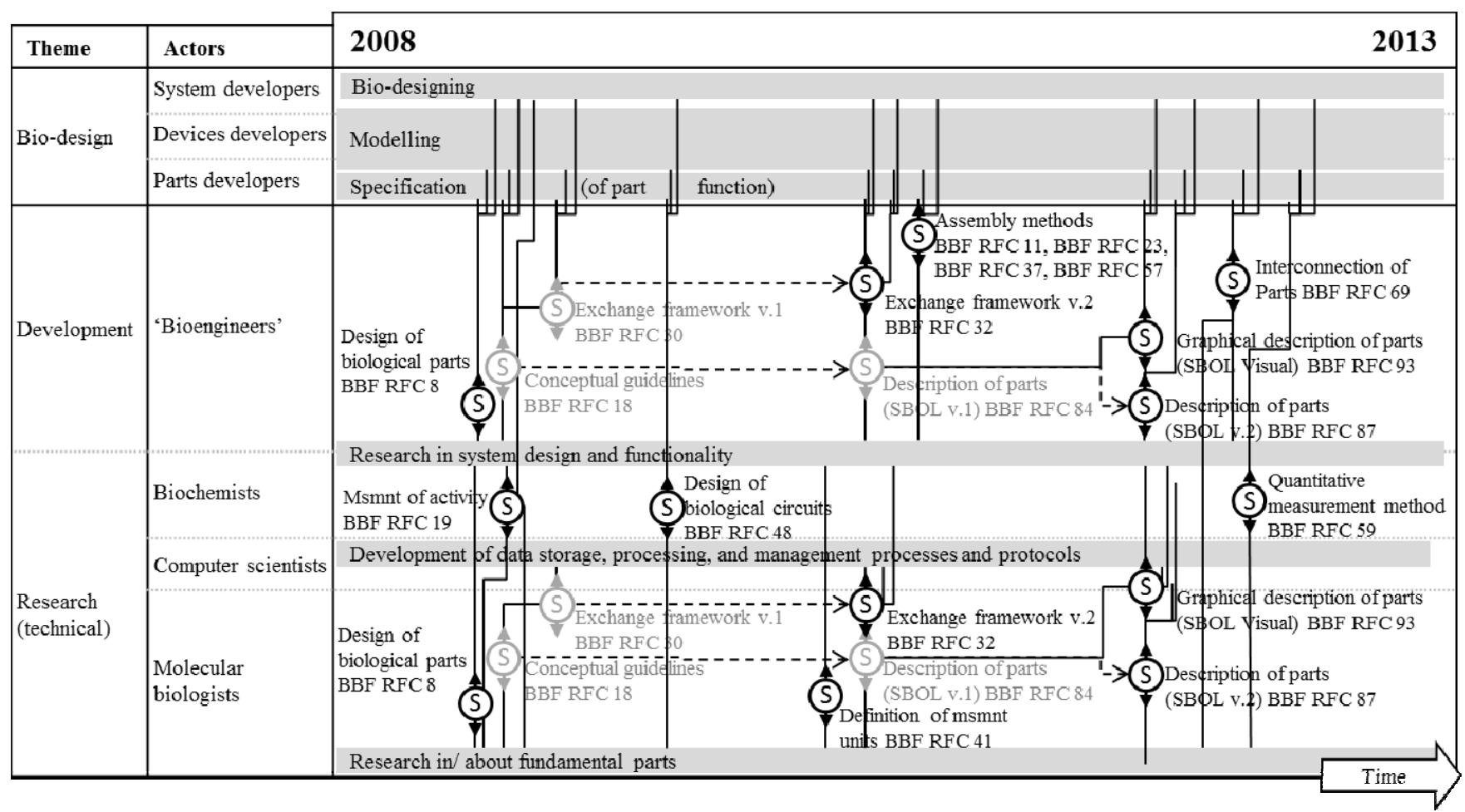

Figure 2: Illustrative example of the framework for synthetic biology

NB: to simplify the diagram visually, some standards have been duplicated

The fundamental nature of the BioBricks Foundation's description of synthetic biological systems - which defines parts, devices, the ways they interact with each other, and the ways they interact within an overall system - means that standards relating to these distinctions are relevant for almost all research activities. The BioBricks Foundation deemed these terminological and semantic distinctions so important that specific standards needed to be developed to diffuse this information (i.e. BBF RFC 87 and BBF RFC 93). Figure 2 indicates that the proposed framework is potentially capable of drawing out fundamental and pervasive standardisation needs such as terminology and semantics (Terminology and semantic reference standards, see section 2.3) through the identification of different research and development activities and their communication and information diffusion needs.

Many of the standards reflected in Figure 2 (e.g. BBF RFC 19 and BBF RFC 48) also indicate the need for the characterisation and measurement of biological parts to support information transmission from innovation activities in the research base to activities related to the further development of circuits. Again Figure 2 indicates that such standardisation needs can be captured and reflected by the framework because of its attention to carefully characterising innovation activities and their knowledge needs.

Figure 2 also illustrates the approach used to identify different types of stakeholders that standards are diffusing information between, based on their involvement in the related innovation activities. The stakeholders identified in Figure 2 include computer scientists, molecular biologists, and bio-designers.

In addition, it reflects the dynamic evolution of standards, which is exemplified by the update of SBOL (a data exchange standard for describing genetic parts and systems). This evolution of standards is presented against a general, relative timeline, with standards being mapped out relatively to each other. 
Figure 2 also indicates that the proposed framework can be tailored to capture the standards-related characteristics of very early stage emerging technological domains, including those aimed at establishing and consolidating a new technology-based community, such as synthetic biology.

Finally, the mapping of the standards reveals the fundamental nature of standards developed at the earlier stages of technology development. The wide influence of the terminology and semantic standards in facilitating diffusion between innovation activities, the number of links between so few clusters of innovation activities, and the importance placed on measurement and characterisation standards for supporting the research-to-development transition indicate how important these standards are for developing technology further in an emerging field.

\subsection{Additive manufacturing}

The term additive manufacturing has a number of synonyms and refers to a number of different technologies. Synonyms often used for it include direct manufacturing, direct digital manufacturing, rapid manufacturing, and 3-dimensional printing (3D printing or 3DP). The technologies referred to by the term additive manufacturing include stereolithography (SL), selective laser sintering/ melting (SLS/M), electron beam melting (EBM), inkjet (or binder jetting), fused deposition modelling (FDM), and laminated object manufacturing (LOM). It also includes a number of material-equipment configurations such as powder-bed infusion (a technique used in SLS, EBM or inkjet) and material 'jetting' (used in SLS, EBM and binder jetting).

Additive manufacturing has a number of advantages over other manufacturing processes. It has the ability to create parts with unique geometries and other unique structural and functional properties, and create net- and near-net-shape parts. As a process it generally has low material wastage, scalability, skills transferability due to digital design and input, versatility, and often reduced change-over costs and time. Additive manufacturing is used to manufacture a range of different products, including toys and trinkets, jewellery, aerospace components, and materials for medical applications, both for tissue production and the fabrication of bio-inert parts, such as prostheses. AM was selected because it is a manufacturing technology that is at different stages of maturity, depending on the specific technology being used and what exactly it is being used to manufacture. This provides contrasting standardisation priorities both within additive manufacturing and between additive manufacturing and the other case studies.

A number of standards have been developed by SDOs for additive manufacturing. For example, ASTM International (ASTM) has developed and is developing standards through the F42 committee, ISO through the Technical Committee 261 (ISO/TC 261), and the British Standards Institution (BSI) through the Advanced Manufacturing Technology Committee 8 (AMT/8 Additive manufacturing). These standards codify different information, have varying roles, and perform different functions. ASTM has classified its published standards relating to additive manufacturing into terminology, materials and processes, design, and test methods. ISO has classified its additive manufacturing related standards according to various categories in the International Classification for Standards (ICS). However, more specific intended roles and functions can be acquired from the description of the standards themselves. The published standards (to-date) and their interpreted roles can be seen in Table 2. The table excludes standards that might apply to additive manufacturing but were not developed specifically for additive manufacturing, such as health and safety standards and product data representation and exchange standards (such as ISO10303). 


\begin{tabular}{|c|c|c|c|c|}
\hline Standard & Date & Title & Role & $\begin{array}{l}\text { Initial } \\
\text { developer }\end{array}$ \\
\hline \begin{tabular}{|l|} 
ASTM \\
F2792 \\
\end{tabular} & 2012 & $\begin{array}{l}\text { Standard Terminology for Additive } \\
\text { Manufacturing Technologies }\end{array}$ & Terminology & ASTM \\
\hline $\begin{array}{l}\text { ISO/AST } \\
\text { M } 52915\end{array}$ & 2013 & $\begin{array}{l}\text { Standard Specification for Additive } \\
\text { Manufacturing File Format (AMF) (v1.1) }\end{array}$ & $\begin{array}{l}\text { Interoperability to } \\
\text { support design }\end{array}$ & ASTM \\
\hline $\begin{array}{l}\text { ASTM } \\
\text { F2971 }\end{array}$ & 2013 & $\begin{array}{l}\text { Standard Practice for Reporting Data for Test } \\
\text { Specimens Prepared by Additive Manufacturing }\end{array}$ & $\begin{array}{l}\text { Test methods and } \\
\text { reporting procedures }\end{array}$ & ASTM \\
\hline $\begin{array}{l}\text { ISO/AST } \\
\text { M 52921 }\end{array}$ & 2013 & $\begin{array}{l}\text { Standard Terminology for Additive } \\
\text { Manufacturing-Coordinate Systems and Test } \\
\text { Methodologies }\end{array}$ & $\begin{array}{l}\text { Test methods and } \\
\text { reporting procedures }\end{array}$ & ASTM \\
\hline $\begin{array}{l}\text { ASTM } \\
\text { F2924 }\end{array}$ & 2014 & $\begin{array}{l}\text { Standard Specification for Additive } \\
\text { Manufacturing Titanium-6 Aluminum-4 } \\
\text { Vanadium with Powder Bed Fusion } \\
\end{array}$ & $\begin{array}{l}\text { Characterisation of } \\
\text { materials and process }\end{array}$ & ASTM \\
\hline $\begin{array}{l}\text { ASTM } \\
\text { F3001 }\end{array}$ & 2014 & $\begin{array}{l}\text { Standard Specification for Additive } \\
\text { Manufacturing Titanium-6 Aluminum-4 } \\
\text { Vanadium ELI (Extra Low Interstitial) with } \\
\text { Powder Bed Fusion }\end{array}$ & $\begin{array}{l}\text { Characterisation of } \\
\text { materials and process }\end{array}$ & ASTM \\
\hline $\begin{array}{l}\text { ASTM } \\
\text { F3049 }\end{array}$ & 2014 & $\begin{array}{l}\text { Standard Guide for Characterizing Properties of } \\
\text { Metal Powders Used for Additive Manufacturing } \\
\text { Processes }\end{array}$ & $\begin{array}{l}\text { Characterisation of } \\
\text { materials and process }\end{array}$ & ASTM \\
\hline $\begin{array}{l}\text { ASTM } \\
\text { F3055 }\end{array}$ & 2014 & $\begin{array}{l}\text { Standard Specification for Additive } \\
\text { Manufacturing Nickel Alloy (UNS N07718) with } \\
\text { Powder Bed Fusion }\end{array}$ & $\begin{array}{l}\text { Characterisation of } \\
\text { materials and process }\end{array}$ & ASTM \\
\hline $\begin{array}{l}\text { ASTM } \\
\text { F3056 }\end{array}$ & 2014 & $\begin{array}{l}\text { Standard Specification for Additive } \\
\text { Manufacturing Nickel Alloy (UNS N06625) with } \\
\text { Powder Bed Fusion }\end{array}$ & $\begin{array}{l}\text { Characterisation of } \\
\text { materials and process }\end{array}$ & ASTM \\
\hline $\begin{array}{l}\text { ASTM } \\
\text { F3091/ } \\
\text { F3091M }\end{array}$ & 2014 & $\begin{array}{l}\text { Standard Specification for Powder Bed Fusion of } \\
\text { Plastic Materials }\end{array}$ & $\begin{array}{l}\text { Characterisation of } \\
\text { materials and process and } \\
\text { Part/process specification } \\
\end{array}$ & ASTM \\
\hline $\begin{array}{l}\text { BS/ISO } \\
17296-3 \\
\end{array}$ & 2014 & $\begin{array}{l}\text { Additive manufacturing - Rapid technologies } \\
\text { (rapid prototyping) Part 3: Test methods }\end{array}$ & $\begin{array}{l}\text { Test methods and } \\
\text { reporting procedures }\end{array}$ & ISO \\
\hline $\begin{array}{l}\mathrm{BS} / \mathrm{ISO} \\
17296-4\end{array}$ & 2014 & $\begin{array}{l}\text { Additive manufacturing - Rapid technologies } \\
\text { (rapid prototyping) Part 4: Data processing }\end{array}$ & $\begin{array}{l}\text { Part specification } \\
\text { (including requirements) } \\
\text { and data processing }\end{array}$ & ISO \\
\hline
\end{tabular}

Table 2: Additive manufacturing standards developed by ASTM and ISO

An illustrative example of the standards shown in Table 2 mapped onto the proposed framework is shown in Figure 3. The only standard not depicted in Figure 3 is terminology standard ASTM F2792 (2012). The standard contains generic definitions of terms used in the field and supports communication between and within all activities within the industry, not only innovation activities. Because of its pervasiveness it is not depicted here to make the illustration clearer and easier to follow (for an illustration of terminology standards, see the synthetic biology case study in section 4.1). For similar reasons the Part characterisation and testing standard ISO/ASTM 52921 (2013), which includes some terminology, is only depicted in its primary function: to communicate part properties between producers and users. 


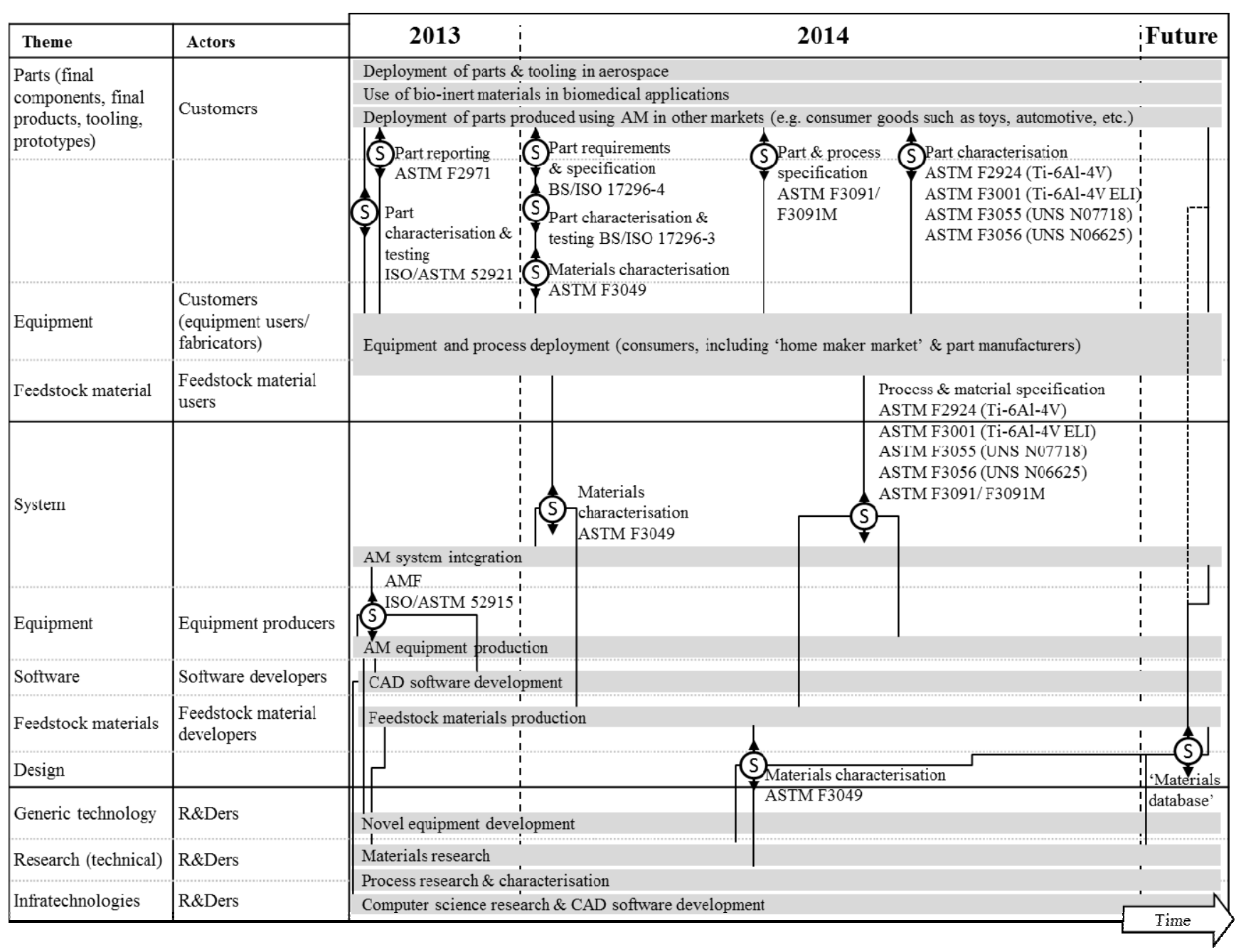

Figure 3: Illustrative example of the framework for additive manufacturing

A review of the standards developed for additive manufacturing indicated that they are designed to support communication between different stakeholders and different innovation activities. The mapping in Figure 3 demonstrates how standards can be depicted in this role. For example, BS/ISO 17296-4 (2014) was developed to standardise data exchange of requested 3D geometries between producers and users, including software engineers, manufacturers, part users, and test bodies. Specification of such information is an important role standards perform (Swann 2010; Hatto 2010; Tassey 2000). This perspective of standards suggests that the links in maps like Figure 3 are themselves a distinct 'diffusion' class of innovation activity, which sit apart from traditional roadmapping themes. It also suggests that such notions might be similarly applicable to other diffusion activities, such as workshops, conferences, and policy development exercises.

The mapping in Figure 3 also reveals that standards (and even clusters of standards) support diffusion between clusters of innovation activities. This is why the innovation activities have been aggregated in Figure 3. BS/ISO 17296-4 (2014) exemplifies this point and illustrates how a number of different stakeholders, engaging in a number of different but similar innovation activities, might use similar guidelines for codifying and transmitting information and knowledge.

Figure 3 also demonstrates how the framework draws out the technical detail related to a technology, unlocking the ability to: identify relevant stakeholders; highlight where standardisation might support bilateral communication; and identify unique standardisation opportunities. First, Figure 3 shows how the 
actors relevant to a standardisation effort, and potentially the development and deployment of a standard, can be identified through the characterisation of innovation activities and the stakeholders evolved in them.

Second, through the innovation activity actors, it demonstrates that the framework can highlight standards that support bi- or multi-lateral communication between actors. For example, BS/ISO 17296-4 (2014) supports the communication of part requirements to manufacturers and part characteristics to users and may also be used to mediate engagement with a third part. This has implications beyond the proposed framework, suggesting that standards not only perform a diffusion function but that they also mediate between the different actors involved in the innovation process.

Third, Figure 3 demonstrates that because the framework helps to characterise the technical detail, it can highlight a variety of standardisation opportunities unrelated to traditional domains, but that are still relevant for a number of different applications. For example, it draws out standards that are application agnostic based on the general needs of the activities, such as characterising input materials (ASTM F3049, 2014), test methods (ISO 17296-3, 2014), and supporting software-equipment interoperability (ISO/ASTM 52915 2013). Furthermore, it highlights common combinations of materials and processes that can be employed in different applications, for example nickel alloy with powder bed infusion (ASTM F3055 2014). This advantage is partilcularly important for complex fields and is made more distinctively because it is exemplified by using additive manufacturing, which draws on research from a variety of domains - including materials development, control systems, and software development - and recombines them in a range of computercontrolled manufacturing processes, which use different input materials to create vastly different parts.

Again, as in the synthetic biology case study (section 4.1), the framework also captures standards as a bridging-medium between key innovation activity clusters (reflected in the aggregations of activities in Figure 3). Many of the standards in the figure support communication between key developer and user groups, such as manufacturers, home-additive manufacturing equipment users, specialist manufacturing firms, and part and tooling users. This shows standards not only as key diffusion and mediation mechanisms, but also as legitimising mechanisms (cf. Lundvall 1992; Ehrnberg and Jacobsson 1997; Bergek et al. 2008; Swann 2010), that can potentailly enahance and provoke the expansion of innovative activity.

Finally, Figure 3 also indicates how the framework can be used to anticipate standards that could be developed to support innovation. The timeline of published standards for additive manufacturing is quite condensed, with standards only having been developed between 2012 and 2014. However, the standard 'Materials database' in Figure 3, is an anticipated standard, which is not yet in development, but is based on the advocations of a number of industry personnel (for example Bryant et al. 2013; Liou 2013). This standard would standardise a way of reporting the mechanical properties of materials produced using AM (perhaps using a database) and how they are to be compared to the same materials produced using traditional approaches; and would be designed to help diffuse this information and mediate between part users, part manufacturers, and feedstock material developers.

\subsection{Smart grid case study}

Smart grid refers to an advanced power grid for the next generation, integrating many varieties of Information and Communications Technology (ICT) and services with the existing power-delivery infrastructure. Bidirectional flows of energy and two-way communication and control capabilities will allow electricity from a diverse range of power plants (including renewable energy) to be delivered to consumers, not only improving power reliability, but also reducing carbon emissions and reliance on oil consumption. Smart grid 
was selected for the study because it is a system of technologies and provides different standardisation priorities to the other case studies.

The development of appropriate and readily available standards is critical in supporting interoperability, integration, and security of smart grid because of its highly complex systemic nature and the large number of stakeholders involved in its operation (O’Sullivan and Brévignon-Dodin 2012). Recognising such importance and urgency of standards-related issues in the field, the Energy Independence Act of the US assigned the NIST the 'primary responsibility to coordinate development of a framework... to achieve interoperability of smart grid devices and systems' (NIST 2010, p.7). NIST has subsequently developed the 'NIST Framework and Roadmap for Smart Grid Interoperability Standards' to help guide and align the development of standards in the smart grid area (NIST 2010).

\begin{tabular}{|c|c|c|c|c|c|}
\hline Standard & Date & Title & Role & Domain & SDO \\
\hline $\begin{array}{l}\text { ANSI } \\
\text { C12.1 }\end{array}$ & 2008 & Code for Electricity Metering & $\begin{array}{l}\text { Measurement / quality for } \\
\text { revenue metering }\end{array}$ & $\begin{array}{l}\text { Customer, Service } \\
\text { Provider }\end{array}$ & ANSI \\
\hline $\begin{array}{l}\text { ANSI } \\
\text { C12.21 }\end{array}$ & 2006 & $\begin{array}{l}\text { Protocol Specification for Telephone Modem } \\
\text { Communication }\end{array}$ & $\begin{array}{l}\text { Interoperability / interface } \\
\text { b/w device and client }\end{array}$ & $\begin{array}{l}\text { Customer, Service } \\
\text { Provider }\end{array}$ & ANSI \\
\hline $\begin{array}{l}\text { IEC } \\
60870-6- \\
503\end{array}$ & $\begin{array}{l}2002, \\
\text { rev in } \\
2014 \\
\end{array}$ & $\begin{array}{l}\text { Telecontrol Equipment and Systems - TASE. } 2 \\
\text { Services and Protocol }\end{array}$ & $\begin{array}{l}\text { Interoperability / interface } \\
\text { b/w control centres }\end{array}$ & $\begin{array}{l}\text { Transmission, } \\
\text { Distribution }\end{array}$ & IEC \\
\hline $\begin{array}{l}\text { IEC } \\
61850-2\end{array}$ & 2003 & $\begin{array}{l}\text { Communication Networks and Systems in } \\
\text { Substations - Glossary }\end{array}$ & Terminology for SAS & $\begin{array}{l}\text { Transmission, } \\
\text { Distribution }\end{array}$ & IEC \\
\hline $\begin{array}{l}\text { IEC } \\
61850-3\end{array}$ & $\begin{array}{l}2002, \\
\text { rev in } \\
2013 \\
\end{array}$ & $\begin{array}{l}\text { Communication Networks and Systems for } \\
\text { Power Utility Automation - General } \\
\text { Requirements }\end{array}$ & $\begin{array}{l}\text { Quality for communication } \\
\text { between IEDs }\end{array}$ & $\begin{array}{l}\text { Transmission, } \\
\text { Distribution }\end{array}$ & IEC \\
\hline $\begin{array}{l}\text { IEC } \\
61850-6\end{array}$ & $\begin{array}{l}2004, \\
\text { rev in } \\
2009\end{array}$ & $\begin{array}{l}\text { Communication Networks and Systems for } \\
\text { Power Utility Automation - Configuration } \\
\text { Description Language for Communication in } \\
\text { Electrical Substations Related to IEDs } \\
\end{array}$ & $\begin{array}{l}\text { Information / variety } \\
\text { reduction for } \\
\text { communication between } \\
\text { IED tools }\end{array}$ & $\begin{array}{l}\text { Transmission, } \\
\text { Distribution }\end{array}$ & IEC \\
\hline $\begin{array}{l}\text { IEC } \\
61850-7-2\end{array}$ & $\begin{array}{l}2003, \\
\text { rev in } \\
2010\end{array}$ & $\begin{array}{l}\text { Communication Networks and Systems for } \\
\text { Power Utility Automation - Basic Information } \\
\text { and Communication Structure - Abstract } \\
\text { Communication Service Interface (ACSI) } \\
\end{array}$ & $\begin{array}{l}\text { Interoperability / interface } \\
\text { for utility automation }\end{array}$ & $\begin{array}{l}\text { Transmission, } \\
\text { Distribution }\end{array}$ & IEC \\
\hline $\begin{array}{l}\text { IEC } \\
61850-10\end{array}$ & $\begin{array}{l}2005, \\
\text { rev in } \\
2012\end{array}$ & $\begin{array}{l}\text { Communication Networks and Systems for } \\
\text { Power Utility Automation - Conformance } \\
\text { Testing }\end{array}$ & $\begin{array}{l}\text { Measurement / testing for } \\
\text { power utility automation }\end{array}$ & $\begin{array}{l}\text { Transmission, } \\
\text { Distribution }\end{array}$ & IEC \\
\hline $\begin{array}{l}\text { IEEE } \\
1815\end{array}$ & 2012 & $\begin{array}{l}\text { Standard for Electric Power Systems } \\
\text { Communications-Distributed Network Protocol } \\
\text { (DNP3) }\end{array}$ & Interoperability / interface & $\begin{array}{l}\text { Generation, } \\
\text { Transmission, } \\
\text { Distribution, } \\
\text { Operations, Service } \\
\text { Provider }\end{array}$ & IEEE \\
\hline $\begin{array}{l}\text { IEEE } \\
1547\end{array}$ & $\begin{array}{l}2003, \\
\text { rev in } \\
2014 \\
\end{array}$ & $\begin{array}{l}\text { Standard for Interconnecting Distributed } \\
\text { Resources with Electric Power Systems }\end{array}$ & $\begin{array}{l}\text { Interoperability for } \\
\text { interconnecting distributed } \\
\text { resources }\end{array}$ & $\begin{array}{l}\text { Transmission, } \\
\text { Distribution, } \\
\text { Customer } \\
\end{array}$ & IEEE \\
\hline $\begin{array}{l}\text { NAESB } \\
\text { REQ18/ } \\
\text { REQ19 }\end{array}$ & 2010 & Energy Usage Information & $\begin{array}{l}\text { Interoperability / interface } \\
\text { for energy usage info. }\end{array}$ & $\begin{array}{l}\text { Customer, Service } \\
\text { Provider }\end{array}$ & $\begin{array}{l}\text { NAES } \\
\text { B }\end{array}$ \\
\hline $\begin{array}{l}\text { NEMA } \\
\text { SG-AMI } \\
1-2009\end{array}$ & 2009 & Requirements for Smart Meter Upgradeability & $\begin{array}{l}\text { Quality requirement for } \\
\text { AMI }\end{array}$ & $\begin{array}{l}\text { Customer, } \\
\text { Distribution }\end{array}$ & $\begin{array}{l}\text { NEM } \\
\text { A }\end{array}$ \\
\hline
\end{tabular}

Table 3: The standards used in the smart grid case study, selected for their variety and varying levels of interdependence

As part of developing the framework and roadmap, NIST has identified 74 standards and guidelines (to-date) developed by various organisations, that support interoperability of smart grid devices and systems (NIST 2014). As the NIST list appears to be the most advanced and updated in this field, a set of standards were selected from it for this case study that demonstrate the effectiveness of the framework for capturing 
standardisation needs that have been addressed by standards with a range of roles, and that have been developed by a variety of SDOs. They were also selected to demonstrate flexibility and effectiveness of the framework. The set of 12 standards selected can be seen in Table 3. The 'domain' column is included in the table, as they are important categories distinguishing various actors and applications involved in smart grid technologies. Identifying the main domains of application (including generation, transmission, distribution, operation, service providers, and customers) helps understand which innovation activities and actors the particular standard transfers knowledge between and provide useful criteria for selecting aggregated innovation activities that contribute to smart grid innovation. Accordingly, the identified standards and relevant innovation activities, along with actors involved in these activities, are mapped onto the standards mapping framework developed in the previous section, as shown in Figure 4.

As smart grid refers to an integrated system of technologies rather than conducting research and development at basic science and technology levels (as opposed to synthetic biology and additive manufacturing), its innovation process mainly involves assembling and linking vast number of devices, products, processes and systems across various domains of smart grid technologies. To demonstrate the framework's ability to reflect these particular priorities, the identified standards were selected because they are communication protocols that establish linkages and interoperability between diverse products and systems, absence of which may result in smart grid technologies becoming prematurely obsolete. Many standards are especially developed in the domains of transmission and distribution, as data exchange and communications need to be made between systems of different utility companies. Standards are also needed to allow communication between products and devices from different manufacturers, hence they can be integrated into the grid in a compatible way.

In addition, various other stakeholders such as regulatory bodies and actors in markets might be involved, when electricity is exchanged in markets or relevant legislations are enacted. Therefore, in order to facilitate innovation of such complex, integrated systems involving various stakeholders, describing how particular products and systems need to be connected within a larger system is essential, as suggested by various scholars and practitioners (Blind and Gauch 2009; BERR 2008); interoperability / interface standards play important roles in this, by supporting communication and establishing linkages across various domains. There are also various other standards with different functions, including information / terminology standards, and measurement / testing standards. For example, IEC 61850-2 contains the glossary of specific terminology and definitions used in the context of substations, whereas IEC 61850-6 specifies a file format for describing device configurations; they appear at a relatively earlier stage of the overall technology lifecycle, suggesting that common terminology and information needs to be established early to facilitate efficient communication among various stakeholders, as noted by Blind and Gauch (2009). There exist other standards that also define recommended measurement techniques for testing of conformance and measuring performance levels, codifying and transmitting knowledge in the form of best practice between various domains involved in the system (Tassey 2000). Therefore, the case study shows that the smart grid standards not only ensure successful integration of products and systems in different domains within a larger system, but also allow knowledge generated and developed in one domain to be diffused into other domains, supporting further innovation.

In addition, the framework is flexible enough to capture various other strategic considerations and dimensions that need to be considered for standardisation strategy development. Standards developed by various organisations with varying approaches, from working groups or technical committees of official SDOs to professional consortiums developing public standards, can be mapped over time. It also captures how standards revisions may be necessary due to revisions of related standards triggered by technological changes 
and advancements, as can be seen from the successive revision of IEC 61850 series regarding communication networks and systems for power utility automation. This further emphasises the sequencing issues identified in the in the previous cases.

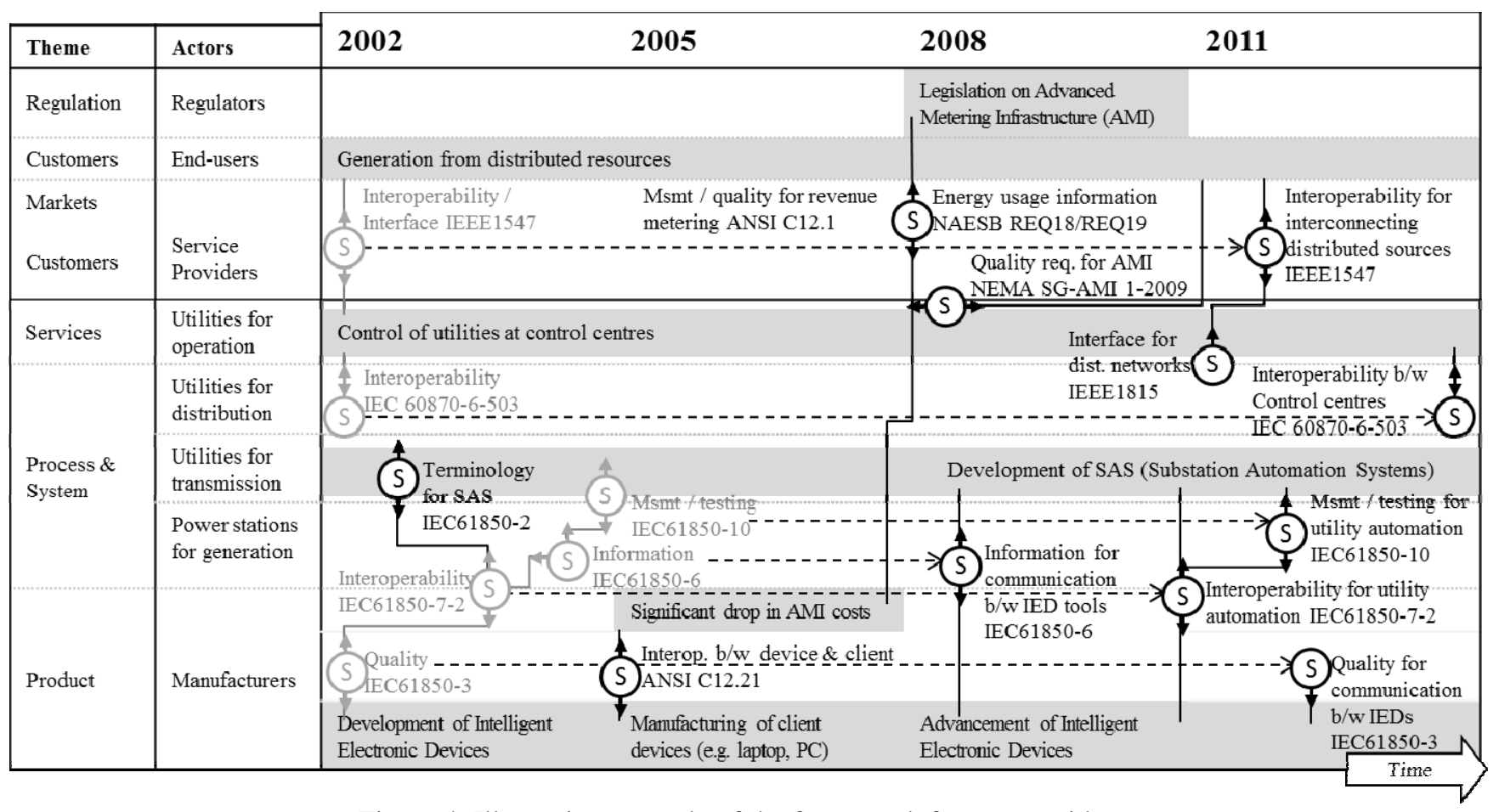

Figure 4: Illustrative example of the framework for smart grid

\section{$5 \quad$ Discussion}

\subsection{Linking standardisation to the process of innovation}

The case studies demonstrate how standardisation can support the specific diffusion needs of innovation activities. This supports the view that standards are enablers of information and knowledge diffusion and help to bridge the gap between research and markets (Blind and Gauch 2009; European Commission 2011). The proposed technology roadmapping-based framework helps to better reveal how standardsrelated activities can support the innovation pathway of emerging technologies by more carefully identifying (aggregated) innovation activities and associated opportunities for standardisation based on their diffusion needs.

The case studies also highlight that standards not only support information and knowledge diffusion, but also help mediate between innovation activities and between actors. The standards in the case studies not only help structure and communicate necessary information, but also facilitate its generation (for example testing in additive manufacturing) and structure how it is communicated both 'forward' to 'future' and 'back' to 'earlier' innovation activities (for example how to describe system elements in synthetic biology). This supports standards as a mechanism for aligning and coordinating innovation activities. The case studies also suggest this mediating function incorporates a 'multilateral nature', where standards can be developed to consider both technology-push and demand-pull factors, and where such considerations mutually affect the actors involved. For example, the ISO additive manufacturing standard for Part specification (see Table 2) identifies not only how a part should be specified for a part user, but also how 
the user can specify the requirements to manufacturers. These findings support Yoo et al.'s (2005) argument that standards help mediate the interests of different actors.

Beyond diffusion and mediation, the case studies also suggest that standards enhance and catalyse innovation. Tassey (2000) asserts that a number of activities already taking place are enhanced by standards, providing examples such as allowing 'factories to achieve economies of scale and enabled markets to execute transactions in an equitable and efficient manner' (p.588). This enhancement can occur in a number of areas, including making these activities cheaper, easier, and faster. The aggregated innovation activities in the case studies also indicate the catalytic nature of standards. For example, the terminology and semantics standards developed for synthetic biology (the development of these rules is itself an innovation activity) enable communication between researchers, developers, and designers, catalysing renewed activity based on the flow of new information and knowledge. These functions diffusion, mediation, enhancement, and catalysis - are important functions standards can play in supporting technology emergence.

\subsection{Drawing attention to some central considerations for standardisation strategies}

While the case studies indicate that standards can be designed to help diffuse information and knowledge, mediate between innovation actors, and enhance and catalyse innovation activities, they also show how the framework has the potential to help coordinate and align standardisation activities. In the synthetic biology and smart grid case studies, for example, a revision of one standard prompted the revision of other dependent standards. The framework can thus help manage a portfolio or 'system' of standards, by identifying and capturing the links between relevant innovation activities and between related standards.

The case studies also demonstrate how the framework can be used to indicate which stakeholders might need to be involved in standards development. Through the characterisation of innovation activities, the framework can be used to link anticipated standardisation activities with the relevant innovation actors, further informing sequencing- and revision-related needs by suggesting the relevant stakeholders to involve. In addition, the framework can support the exploration of the possible roles of government and government agencies in standardisation, specifically where they can undertake a leadership, coordinating, or convening functions to further promote standardisation activities.

The case studies reinforce Blind and Gauch's (2009) argument that particular types of standards are associated with particular stages of a technology lifecycle. The synthetic biology case study, for example, suggests that semantic standards are developed in the early stages of a technology lifecycle, linking pure basic research to oriented basic research (Blind and Gauch 2009). Standards in other case studies link different stages of technology lifecycle identified by Blind and Gauch (2009), including additive manufacturing's measurement and testing standards (bridging to applied research); smart grid's interface standards (bridging to experimental development); and various compatibility, quality, and variety reduction standards (bridging to technology diffusion). However, despite the varying maturity of the fields addressed in the case studies, the timing of particular types of standards are not reflected as clearly or as linearly as Blind and Gauch (2009) suggest. This is possibly due to the nonlinearity of technology development (acknowledged by Blind and Gauch 2009), the different timeframes between identification of standards needs and their publication, or the various technologies within each field being at different stages of development. Nevertheless, one obvious trend in all case studies is the early development of terminology standards, confirming Blind and Gauch's (2009) argument and Ho and O’Sullivan's (2013) findings that these standards are some of the earliest to be developed. 
The case studies also demonstrate that the established flexibility and scalability of technology roadmapping has been retained. They indicate that the framework can accommodate a range of different types of standards, in different domains, with different actors, and applied to different end markets and that the horizontal categories proved to be easily selected and removed from the framework for reasons of relevance and the clear visualisation of standardisation opportunities.

The literature relating to standards, supported by the case studies, suggest that important considerations for developing standardisation strategies include: the different standardisation needs of different stages of technology development, the different types of standards that can be developed, the evolving composition of stakeholders, and the timing and sequencing of different standards. The case studies offer a proof of principle that the framework is capable of capturing these strategic considerations and dimensions which were identified as important in the standards literature (see section 2.0). Furthermore, the case studies suggest that these considerations and dimensions are interdependent, hence there is potentially considerable benefit in being able to explore and consider them jointly.

Furthermore, scanning activities could be guided by the framework to identify potentially competing standards and those in closely related technology fields. For instance, some standards developed for systems biology can also be used to support synthetic biology-based products and processes. Scanning for, and mapping, such standards help to not only provide 'anticipatory intelligence to system actors,' but also 'inform policy' and strategy development, which are key characteristic of foresight exercises (Miles et al. 2008, p.20), and could help streamline standardisation processes.

\subsection{Implications of the framework}

The framework neither suggests that all standards requirements can be anticipated, nor recommends making all identified standards de jure. Instead it is suggested that the framework can be used to identify standardisation opportunities. This view indicates that the framework could also identify standards that might emerge naturally from interactions ('unsponsored' de facto standards), as well as those that could be formally developed either by SDOs or governments (de jure standards) or by industry consortia or firms ('sponsored' de facto standards).

The historical approach embraced in the case studies demonstrates the validity of the framework in capturing the relevant innovation dimensions and components to reveal important standardisation opportunities and challenges. By capturing such considerations, the case studies provide an early 'proof of concept' and suggest applying the framework in an anticipatory setting. An example of how standards anticipation may be depicted is given in the additive manufacturing case study. The example demonstrates how the framework has retained the intrinsic future orientated focus of technology roadmapping, a core characteristic of technology foresight. A practical application, and its assessment over time, is recommended to evaluate just how useful the framework is for anticipating future standardisation opportunities.

\section{Conclusions}

The presented framework is designed to inform where standardisation may be important and where efforts could be invested to overcome particular challenges in development technology. The proposed framework incorporates a number of critical strategic considerations and dimensions important for standards development, including technological innovation activities, standards types, SDOs and participants, and 
the timing of standards. The framework was anchored in technology roadmapping, a practical technology innovation framework that takes account of complex technical systems and spans key areas of risk, opportunity, and challenges. This foundation helps the framework to draw out the innovation activities and technology development's time dependent nature. The proposed framework builds on these features, adding the consideration of multiple types of standardisation and explicitly identifying the relevant, and changing, composition of stakeholders. The proposed framework combines these features (strategic considerations and dimensions), using a more detailed characterisation of innovation activities to reveal where standardisation might be used to diffuse information and knowledge, mediate between innovation actors, and potentially enhance and catalyse innovation activities, ultimately supporting an emerging technology.

The framework could be used to leverage current or past technology roadmapping exercises to identify standardisation needs. At the very least, the proposed framework's key dimensions could be used to point to potentially important standardisation opportunities and challenges in existing standardisation or technology foresight exercises.

Three 'historical' case studies of recent emerging technologies were offered to 'prove the principles' and demonstrate the utility of the framework. The case studies suggest that the proposed framework can capture and bring clarity on the aforementioned strategic considerations and dimensions and to other strategic considerations that might otherwise be overlooked, including alignment, coordination, and sequencing. All of these considerations and dimensions proved critical to understanding the role of standardisation in the emergence of the case study technologies. The importance and relevance of the above considerations enhance previous contributions to the literature on standards.

Furthermore, the historical case studies indicate that the framework was customisable enough to reflect a variety of innovation activities, capture a variety of different roles standards fulfil, and accommodate different types of standards, while retaining the flexibility and adaptability of technology roadmapping.

The case studies also suggest that standards support technology development in a rich and complex way, upholding a number of authors, including Tassey (2000). However, the case studies also point to the importance of the appropriate design, timing, and coordination of standards, bolstering Allen and Sriram's (2000) claims that standards can both help and hinder technological development. This urges caution when developing standards specifically to support technology development.

The strategic considerations and dimensions underpinning the framework (time, innovation activities, stakeholders, standardisation types) help reveal information that can help to avoid hindering technology development and support the development of an appropriately designed and coordinated portfolio of standards. The clarity provided by the framework, and the visual form it can take (see case studies), can help navigate the complexity involved in the development of such standardisation strategies, which, as suggested by their potential to both facilitate and hinder technology development, should be an integral part of technology development strategies.

More specifically, the framework, through such standardisation strategies, can also be used to inform technology investment decisions - either in standards or technology development directly - and grant conditions, for example including standards development exercise participation conditions, as called for by the European Commission (2008) and suggested by CEN and CENELEC (2012; 2014). 
Future research should test the framework in a greater variety of technical domains and review its efficacy at anticipating relevant and applicable standardisation needs. Further research could also link the framework and its anticipated standards more closely to the functions of innovation systems approaches (Johnson 2001; Bergek et al. 2010), to establish just how these informed standards are facilitating the functioning of the innovation system.

Finally, our case studies show that standardisation is not just bureaucracy, not just about diffusing 'rules', not just something that happens after all the key research and innovation breakthroughs have taken place. They suggests that standardisation can happen from the earliest phases of technology emergence, mediates many critical innovation activities, and embodies many fundamental characteristics of innovation itself including its evolutionary, feedback-driven, nonlinear nature. Consequently, a detailed, sophisticated, and systemic consideration of standardisation should be an integral part of a comprehensive emerging technology strategy. The framework proposed here can be deployed to make an early contribution to the development of such strategies.

\section{References}

- ANSI, 2014. ANSI Essential Requirements: Due process requirements for American National Standards, American National Standards Institute (ANSI): New York, NY.

- Amer, M., Daim, T.U., 2010. Application of technology roadmaps for renewable energy sector. Technological Forecasting and Social Change, 77(8), pp.1355-1370.

- Allen, R.H., Sriram, R.D., 2000. The Role of Standards in Innovation. Technological Forecasting and Social Change, 64(2-3), pp.171-181.

- BERR, 2008. Regulation and innovation: evidence and policy implications (BEER Economics Paper No. 4). Department for Business, Enterprise and Regulatory Reform (BERR): London, UK.

- BMBF, 2010. Ideas. Innovation. Prosperity. High-Tech Strategy 2020 for Germany. Federal Ministry of Education and Research: Bonn, Germany.

- $\quad$ BSI , 2006. Introducing Standards. British Standards Institute (BSI): London, UK.

- Bergek, A., Jacobsson, S., Carlsson, B., Lindmark, S., Rickne, A., 2008. Analyzing the functional dynamics of technological innovation systems: A scheme of analysis. Research Policy, 37(3), pp.407-429.

- Bergek, A., Jacobsson, S., Hekkert M.P., Smith, K., 2010. Functionality of Innovation Systems as a Rationale for and Guide to Innovation Policy. In Smits, R.E., Kuhlmann, S., Shapira, P. (Eds), The Theory and Practice of Innovation Policy: An International Research Handbook. Edward Elgar: Cheltenham, UK (pp. 115-144).

- Blackwell, A.F., Phaal, R., Eppler, M., Crilly, N., 2008. Strategy Roadmaps: New Forms, New Practices. In 5th International Conference on Diagrammatic Representation and Inference. Springer-Verlag: Berlin \& Heidelberg, Germany (pp.127-140).

- Blind, K., Gauch, S., 2009. Research and standardisation in nanotechnology: evidence from Germany. The Journal of Technology Transfer, 34(3), pp.320-342.

- Blind, K., Gauch, S., Hawkins, R., 2010. How stakeholders view the impacts of international ICT standards. Telecommunications Policy, 34(3), pp.162-174. 
- Bourell, D.L., Leu, M.C., Rosen, D.W., 2009. Roadmap for Additive Manufacturing: Identifying the Future of Freeform Processing. Laboratory for Freeform Fabrication Advanced Manufacturing Center, The University of Texas at Austin: Austin, TX.

- Bourell, D.L., Rosen, D.W., Leu, M.C., 2014. The roadmap for additive manufacturing and its impact. 3D Printing and Additive Manufacturing, 1(1), pp.6-9.

- Brady, R.A., 1933. The Rationalization Movement in German Industry, Berkeley: University of California Press.

- Brévignon-Dodin, L., O’Sullivan, E., 2013. Standards development in support of the Europe 2020 "smart growth" objective - Evidence from Germany and the USA. In 17th EURAS Annual Standardisation Conference: Boosting European Competitiveness. Brussels, Belgium.

- Bryant, J.G., Benfer, J.E., Petrizzo, A.B. (NAVAIR J., FRCSE), 2013. Measurement Barriers in the Implementation of Metals Additive Manufacturing for Military Aircraft Repair and Maintenance. In Energetics Incorporated (Ed.), Measurement Science Roadmap for Metal-Based Additive Manufacturing. Prepared for the National Institute of Standards and Technology (NIST). NIST: Columbia, MD (pp. 63-64).

- CEN, CENELEC, 2012. Integrating Standards in Your FP7: Linking R\&D and Standardization: European Committee for Standardization (CEN) and European Committee for Electrotechnical Standardization (CENELEC): Brussels, Belgium.

- CEN, CENELEC, 2014. Integrating Standards in Your Horizon 2020 Project: Linking Innovation and Standardization. European Committee for Standardization (CEN) and European Committee for Electrotechnical Standardization (CENELEC): Brussels, Belgium.

- Choi, D.G., Lee, H., Sung, T., 2011. Research profiling for “standardization and innovation.” Scientometrics, 88(1), pp.259-278.

- Cisco Systems, 2003. Vision 2010: The Retail Roadmap for Chief Executives, Cisco Systems, Inc.: San Jose, CA.

- Dosi, G., 1982. Technological paradigms and technological trajectories. Research Policy, 11(3), pp.147-162.

- EXPRESS, 2010. Standardization for a Competitive and Innovative Europe: a Vision for 2020.

- Edquist, C., 1999. Innovation Policy - A Systemic Approach. Department of Technology and Social Change working paper. Linköping: Linköping University.

- Ehrnberg, E., Jacobsson, S., 1997. Technological Discontinuities and Incumbents' Performance: An Analytical Framework. In Edquist, C. (Ed.), Systems of Innovation: Technologies, Institutions and Organizations. Pinter: London, UK (pp. 318-341).

- Endy, D., 2005. Foundations for engineering biology. Nature, 438, pp.449-453.

- European Commission, 2008. Communication from the Commission. Towards an increased contribution from standardisation to innovation in Europe. European Commission: Brussels, Belgium.

- European Commission, 2011. Communication from the Commission. A strategic vision for European standards: Moving forward to enhance and accelerate the sustainable growth of the European economy by 2020. European Commission: Brussels, Belgium.

- European Commission, 2013. 2013 Rolling Plan for ICT Standardisation, European Commission: Brussels, Belgium.

- Featherston, C.R., Ho, J.-Y., Brévignon-Dodin, L., O’Sullivan, E., 2014. Technology roadmapping approach in support of standardisation needs for emerging technologies: Guiding and structuring the exploration of standards needs, Institute for Manufacturing, University of Cambridge: Cambridge, UK. 
- Foray, D., 1998. Standards and innovation in technological dynamics. StandardView, 6(2), pp.8184.

- Ford, S.J., Routley, M.J., Phaal, R., Probert, D.R., 2012. Capturing past experience: the Expert Scan visual mapping process. International Journal of Technology Intelligence and Planning, 8(1), pp.47-59.

- Galvin, R., 1998. Science Roadmaps. Science, 280(5365), p.803.

- Gandal, N., 1995. Competing Compatibility Standards and Network Externalities in the PC Software Market. The Review of Economics and Statistics, 77(4), pp.600-608.

- Garcia, M., Bray, O., 1997. Fundamentals of technology roadmapping, Sandia National Laboratories: Albuquerque, NM.

- Geels, F.W., 2002. Technological transitions as evolutionary reconfiguration processes: a multilevel perspective and a case-study. Research Policy, 31(8-9), pp.1257-1274.

- Groenveld, P., 1997. Roadmapping integrates business and technology. Research-Technology Management, 40(5), pp.48-55.

- Groenveld, P., 2007. Roadmapping integrates business and technology. Research-Technology Management, 50(6), pp.49-58.

- HLG KET, 2011. High-Level Expert Group on Key Enabling Technologies: Final Report, European Commission, DG Enterprise and Industry: Brussels, Belgium.

- Hanseth, O., Monteiro, E., Hatling, M., 1996. Developing information infrastructure: The tension between standardization and flexibility. Science, Technology \& Human Values, 21(4), pp.407426.

- Hatto, P., 2010. Standards and Standardization Handbook, European Commission: Brussels, Belgium.

- Ho, J.-Y., O’Sullivan, E., 2013. Evolving Roles of Standards in Technological Innovation Evidence from Photovoltaic Technology. In 35th DRUID Celebration Conference. Barcelona: Spain.

- Ho, J.-Y., O'Sullivan, E., 2014. Defining and Categorising 'Standards' in Innovation. Working Paper, Centre for Science Technology and Innovation Policy, University of Cambridge.

- IBM, 2002. Integrated multi-channel retailing (IMCR): A roadmap to the future. IBM Corporation: Somers, NY.

- ISO, 2004. Standardization and related activities - General vocabulary, ISO/IEC Guide 2:2004.

- Jereza, K., Brindle, R., Williams, G., Chappell, J., 2005. Magnesium Casting Industry Technology Roadmap. Sponsored by the American Foundry Society. Energetics Incorporated: Columbia, MD.

- Johnson, A., 2001. Functions in innovation system approaches. In Documento presentado a la Conferencia Nelson-Winter. Aalborg, Denmark (pp.1-19).

- Keasling, J., 2005. The promise of synthetic biology. The Bridge, 35(4), pp.18-21.

- Keenan, M., 2003, Identifying emerging generic technologies at the national level: the UK experience. Journal of Forecasting, 22(2-3), pp.129-160.

- Kostoff, R.N., Schaller, R.R., 2001. Science and technology roadmaps. IEEE Transactions on Engineering Management, 48(2), pp.132-143.

- Kristiansen, E.G., 1998. R\&D in the Presence of Network Externalities: Timing and Compatibility. The RAND Journal of Economics, 29(3), pp.531-547.

- de Laat, B., Mckibbin, S., 2003. The Effectiveness of Technology Road Mapping, Dutch Ministry of Economic Affairs: Den Haag, The Netherlands. 
- Lee, S. , Park, Y., 2005. Customization of technology roadmaps according to roadmapping purposes: Overall process and detailed modules. Technological Forecasting and Social Change, 72(5), pp.567-583.

- Liou, F., 2013. Measurement Science Barriers and R\&D Opportunities for the NIST Metal-Based AM Workshop. In Energetics Incorporated (Ed.), Measurement Science Roadmap for MetalBased Additive Manufacturing. Prepared for the National Institute of Standards and Technology (NIST). NIST: Columbia, MD (pp. 61-62).

- Lord Heseltine, 2012. No Stone Unturned in Pursuit of Growth, Department of Business, Innovation and Skills (BIS): London, UK.

- Lundvall, B.-Å., 1992. National Systems of Innovation: Towards a Theory of Innovation and Interactive Learning, Pinter: London, UK.

- Metcalfe, J.S., Miles, I., 1994. Standards, selection and variety: an evolutionary approach. Information Economics and Policy, 6(3), pp.243-268.

- Miles, I., Harper, J.C., Georghiou, L., Keenan, M., Popper, R., 2008. The Many Faces of Foresight. In Georghiou, L., Harper, J.C., Keenan, M., Miles, I., Popper, R. (Eds.), The Handbook of Technology Foresight: Concepts and Practice, Edward Elgar: Cheltenham, UK (pp. 3-23).

- NAKFI, 2010. National Academies Keck Future Initiative on Synthetic Biology: Building a Nation's Inspiration: Interdisciplinary Research Team Summaries, Washington, D.C.: The National Academies Press.

- NASA, 2010. Global Exploration Roadmap. NASA: Washington D.C.

- NIST, 2010. NIST Framework and Roadmap for Smart Grid Interoperability Standards, Release 1.0, NIST: Gaithersburg, MD.

- NIST, 2011. Effectiveness of Federal Agency Participation in Standardisation Activities in Select Technology Sectors: Summary of the responses to the National Science and Technology Council's Sub-Committee on Standards Request-for-Information. NIST: Gaithersburg, MD:

- NIST, 2012. NIST Framework and Roadmap for Smart Grid Interoperability Standards, Release 2.0. NIST: Gaithersburg, MD.

- NIST, 2014. NIST Framework and Roadmap for Smart Grid Interoperability Standards, Release 3.0. NIST: Gaithersburg, MD.

- NSTC, 2011a. National Nanotechnology Initiative: Strategic Plan. Executive Office of the President of the United States: Washington, D.C.

- NSTC, 2011b. Federal Engagement in Standards Activities to Address National Priorities: Background and Proposed Policy Recommendations. Executive Office of the President of the United States: Washington, D.C.

- NSTC, 2014. National Nanotechnology Initiative: Strategic Plan. Executive Office of the President of the United States: Washington, D.C.

- Nemet, G.F., 2009. Demand-pull, technology-push, and government-led incentives for nonincremental technical change. Research Policy, 38(5), pp.700-709.

- O’Sullivan, E., Brévignon-Dodin, L., 2012. Role of Standardisation in support of Emerging Technologies. Institute for Manufacturing, University of Cambridge: Cambridge, UK.

- $\quad$ Phaal, R., O’Sullivan, E., Routley, M.J., Ford, S.J., Probert, D.R., 2011. A framework for mapping industrial emergence. Technological Forecasting and Social Change, 78(2), pp.217-230.

- $\quad$ Phaal, R., Farrukh, C.J.P., Probert, D.R., 2004. Customizing Roadmapping. Research Technology Management, 47(2), pp.26-37. 
- Phaal, R., Farrukh, C.J.P., Probert, D.R., 2005. Developing a technology roadmapping system. In Technology Management: A Unifying Discipline for Melting the Boundaries. IEEE, pp. 99-111.

- Phaal, R., Farrukh, C.J.P., Probert, D.R., 2009. Visualising strategy: a classification of graphical roadmap forms. International Journal of Technology Management, 47(4), pp.286-304.

- Phaal, R., Farrukh, C.J.P., Probert, D.R., 2010. Roadmapping for Strategy and Innovation: Aligning Technology and Markets in a Dynamic World. Institute for Manufacturing, University of Cambridge: Cambridge, UK.

- Phaal, R., Muller, G., 2009. An architectural framework for roadmapping: Towards visual strategy. Technological Forecasting and Social Change, 76(1), pp.39-49.

- Popper, R., 2008. Foresight Methodology. In Georghiou, L., Harper, J.C., Keenan, M., Miles, I., Popper, R. (Eds.), The Handbook of Technology Foresight. Edward Elgar: Cheltenham, UK (pp. 44-88).

- $\quad$ Probert, D.R., Shehabuddeen, N., 1999. Technology road mapping: the issues of managing technology change. International Journal of Technology Management, 17(6), pp.646-661.

- SASAM, 2014. Additive Manufacturing: SASAM Standardisation Roadmap, The European Technology Platform Manufuture: s.l.

- Sahal, D., 1985. Technological guideposts and innovation avenues. Research Policy, 14(2), pp.61-82.

- Saritas, O., Oner, M.A., 2004. Systemic analysis of UK foresight results. Technological Forecasting and Social Change, 71(1-2), pp.27-65.

- Scapolo, F., Churchill, P., Viaud, P., Antal, M., Cordova, H., Smedt, P., 2014. Final Report of the Foresight Study on "How will standards facilitate new production systems in the context of EU innovation and competitiveness in 2025?”. European Commission - Joint Research Centre: Brussels, Belgium.

- Sherif, M., 2001. A framework for standardization in telecommunications and information technology. IEEE Communications Magazine, April, pp.94-100.

- Silverman, P.J., 2002. The Intel Lithography Roadmap. Intel Technology Journal, 6(2), pp. 55-61.

- Smith, K., 1997. Economic Infrastructures and Innovation Systems. In Edquist, C., (Ed.), Systems of Innovation: Technologies, Institutions and Organizations. Pinter: London, UK (pp. 86-106).

- Smith, K., 2000. Innovation as a Systemic Phenomenon: Rethinking the Role of Policy. Enterprise and Innovation Management Studies, 1(1), pp.73-102.

- Swann, G.M.P., 2010. The Economics of Standardization: An Update. Report for the UK Department of Business, Innovation and Skills (BIS).

- Swann, G.M.P., 2000. The Economics of Standardization. Final Report for Standards and Technical Regulations Directorate, Department of Trade and Industry (DTI).

- TESSY, 2008. Final report: TESSY Achievements and Future Perspectives in Synthetic Biology, Karlsruhe, Germany: Fraunhofer Institute Systems and Innovation Research.

- TSB, 2012. A synthetic biology roadmap for the UK. Technology Strategy Board (TSB): London, UK.

- Tassey, G., 2000. Standardization in technology-based markets. Research Policy, 29(4-5), pp.587602.

- Tassey, G., 2005. Underinvestment in public good technologies. The Journal of Technology Transfer, 30(1-2), pp.89-113.

- Tassey, G., 2007. The Technology Imperative, Cheltenham, UK: Edward Elgar. 
- Torrance, A.W., Kahl, L.J., 2012. Bringing Standards to Life: Synthetic Biology Standards and Intellectual Property. Santa Clara High Technology Law Journal, 30(2).

- US International Trade Commission, 1990. The Effects of Greater Economic Integration Within the European Community on the United States: First Follow-up Report (USITC Publication 2268). US International Trade Commission: Washington, D.C., USA.

- Utterback, J.M., 1994. Mastering the Dynamics of Innovation: How Companies Can Seize Opportunities in the Face of Technological Change, Harvard Business School Press: Boston, MA.

- Van de Ven, A.H., 1993a. A community perspective on the emergence of innovations. Journal of Engineering and Technology Management, 10(1-2), pp.23-51.

- Van de Ven, A.H., 1993b. The development of an infrastructure for entrepreneurship. Journal of Business Venturing, 8(3), pp.211-230.

- Wang, J., Kim, S., 2007. Time to get in: The contrasting stories about government interventions in information technology standards (the case of CDMA and IMT-2000 in Korea). Government Information Quarterly, 24(1), pp.115-134.

- Willetts, R.H.D.M., 2013. Eight Great Technologies, Policy Exchange: London, UK.

- Yoo, Y., Lyytinen, K., Yang, H., 2005. The role of standards in innovation and diffusion of broadband mobile services: The case of South Korea. The Journal of Strategic Information Systems, 14(3), pp.323-353.

\section{Acknowledgements}

Thanks are due to colleagues in BIS, BSI, TSB and Innovate UK for insights, useful conversations and advice on technological domains, and to BIS, BSI and The Gatsby Foundation for their financial support. 